\title{
Mecanismo de ação da clorexidina sobre as enzimas metaloproteinases e sua repercussão clínica: um estudo de revisão
}

\section{Mechanism of action of chlorhexidine on metalloproteinase enzymes and their clinical impact: a review study}

Valdeci Elias dos Santos Junior Julia Dantas Gomes Lyra**

Marília Bizinoto Silva***

Mônica Vilela Heimer ${ }^{* * * *}$

Aronita Rosenblatt ${ }^{* * * *}$

\section{Resumo}

Objetivo: analisar o mecanismo de ação da clorexidina sobre as enzimas matrizes metaloproteinases (MMPs) e sua repercussão clínica. Materiais e método: a estratégia de busca incluiu as bases de dados Medline, Lilacs e Pubmed. A seleção dos artigos foi feita com base nos seguintes critérios: ter sido escrito em inglês, espanhol ou português, no formato de artigo original, com resumos disponíveis, abordar aspectos que relacionem as MMPs aos sistemas adesivos e/ou a influência da clorexidina sobre estas enzimas, e ter sido publicado entre os anos de 2005 a 2015. Resultados: foram encontrados 34 artigos, porém, após a análise crítica dos resumos, apenas 18 estudos foram incluídos. Considerações finais: o uso da clorexidina como primer terapêutico após o condicionamento ácido previne a ativação da enzima metaloproteinase que degrada a rede de colágeno causando falhas em restaurações adesivas. Logo, o uso de tal substância deve ser estimulado para evitar falhas em restaurações adesivas, aumentando o tempo de vida útil dessas.

Palavras-chave: Clorexidina. Colágeno. Dentina. Restauração.

\section{Introdução}

A dentina humana é composta por tecido mineralizado envolto por uma matriz extracelular. Além do colágeno tipo I, proteínas não colagenosas compõem essa matriz e, dentre essas, há de se destacar as matrizes metaloproteinases (MMPs) $)^{1-4}$. As MMPs encontradas na dentina são produzidas pelos odontoblastos durante a produção da matriz extracelular e, após a calcificação da dentina, essas enzimas permanecem em sua forma inativa ${ }^{3,4}$. Entretanto, podem ser reativadas durante o processo carioso, devido à acidez do meio, propiciando a degradação da rede de colágeno $0^{1,2,5-12}$.

Assim como o desenvolvimento do processo carioso, a atuação de condicionadores ácidos para o emprego de sistemas adesivos, seja nos sistemas de condicionamento ácido total ou auto condicionantes, também pode ativar as MMPs ${ }^{3,4,7-9}$, possibilitando a degradação da matriz de colágeno. A consequência dessa degradação é a falha na adesividade de restaurações em resina composta ${ }^{13-17}$. Portanto, na tentativa de evitar estas falhas, alguns inibidores

Pós-Doutor, Doutor e Mestre em Odontopediatria pela Universidade de Pernambuco - FOP/UPE

Mestre em Ciências da Saúde pela Universidade de Brasília - UnB.

**** Doutora e Mestre em Odontopediatria e Professora Adjunta da Faculdade de Odontologia de Pernambuco - FOP/UPE - Departamento de Saúde Pública.

****** Pós-Doutora, Doutora e Mestre em Odontopediatria e Professora titular da Universidade de Pernambuco - FOP/UPE - Departamento de Odontopediatria. 
de MMPs têm sido incorporados tanto à camada híbrida quanto aos sistemas adesivos, sendo a clorexidina a substância considerada mais promissora ${ }^{1-4,18}$.

Dessa forma, o objetivo do estudo foi verificar, por meio de uma revisão da literatura, o mecanismo de ação da clorexidina sobre as enzimas metaloproteinases (MMPs) e sua repercussão clínica sobre a adesividade de restaurações em resina compostas.

\section{Materiais e método}

A estratégia de busca para a realização desta revisão incluiu artigos indexados na Medical Literature Analysis and Retrieval System Online (Medline), Literatura Latino-Americana de Ciências da Saúde (Lilacs), e no National Library of Medicine (Pubmed). Utilizou-se os seguintes descritores: "chlorhexidine", "metalloproteinase", "adhesive", "clorexidina", "metaloproteinase", "adesivo", reconhecidos pelo vocabulário DeCS/MeSH. Em seguida, foram feitos os cruzamentos dos descritores.

Os critérios de inclusão foram: ter sido escrito em inglês, espanhol ou português, com resumos disponíveis nas bases de dados, no período de 2005 a 2015 e que abordassem aspectos que relacionassem as MMPs aos sistemas adesivos e/ou à influência da clorexidina sobre essas enzimas. Excluiu-se dessa seleção os artigos que se encontravam em duplicata nas bases de dados e estudos que não se apresentavam em formato de artigo, como guidelines, cartas, editoriais, teses e dissertações (Figura 1).

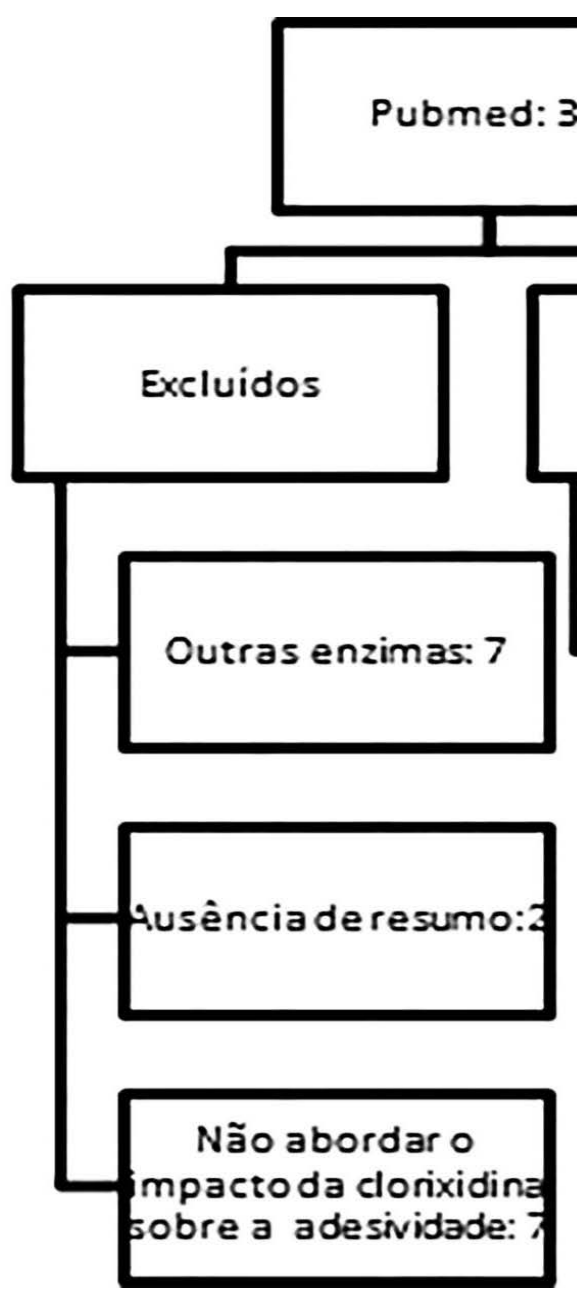

Fluxograma 1: Processo de seleção dos artigos do estudo

\section{Resultados}

Foram encontrados 34 estudos elegíveis, dos quais apenas 18 preencheram os critérios de inclusão. Sete artigos foram excluídos por abordar a influência da clorexidina sobre outras enzimas que não as metaloproteinases, sete foram excluídos por não abordar a influência da clorexidina sobre as restaurações adesivas, dois por não possuir um resumo disponível e/ou não conter informações suficientes e um por estar em duplicata quando se comparou as bases de dados.

No Quadro 1, pode-se observar os estudos incluídos e suas principais conclusões. 
Quadro 1: Estudos incluídos e principais conclusões

\begin{tabular}{|c|c|c|c|c|}
\hline Título & Autores & Ano & Tipo de estudo & Conclusão \\
\hline $\begin{array}{l}\text { The effects of matrix-metallo- } \\
\text { proteinases and chlorhexidine } \\
\text { on the adhesive bond }\end{array}$ & $\begin{array}{l}\text { Strobel S, } \\
\text { Hellwig E }\end{array}$ & 2015 & $\begin{array}{l}\text { Revisão } \\
\text { Sistemática }\end{array}$ & $\begin{array}{l}\text { Quando a clorexidina é usada como um primer terapêutico, após o uso do } \\
\text { ácido fosfórico a } 37 \% \text {, as MMPs são inibidas de um modo não específico, } \\
\text { de tal modo que a camada híbrida e a força adesiva da dentina são } \\
\text { supostamente preservadas por um longo período de tempo. A utilização } \\
\text { de uma solução aquosa pura a } 0,2 \% \text { de clorexidina como um primer } \\
\text { terapêutico adicional pode ser recomendada para sistemas etch-and-rinse. }\end{array}$ \\
\hline $\begin{array}{l}\text { Role of dentin MMPs in caries } \\
\text { progression and bond stability }\end{array}$ & $\begin{array}{l}\text { Mazzoni A } \\
\text { et al. }\end{array}$ & 2015 & $\begin{array}{l}\text { Revisão } \\
\text { Sistemática }\end{array}$ & $\begin{array}{l}\text { Devido ao envolvimento das MMPs na progressão da cárie e na } \\
\text { estabilidade da restauração, inibidores das MMPs podem desempenhar } \\
\text { um papel crucial nos protocolos terapêuticos e preventivos inovadores. } \\
\text { No entanto, são necessários mais estudos sobre novos produtos químicos } \\
\text { capazes de inibir a atividade das MMPs, contribuindo, efetivamente, para } \\
\text { a prevenção da cárie e a melhoria da estabilidade da interface adesiva. }\end{array}$ \\
\hline $\begin{array}{l}\text { Ethanol-wet Bonding } \\
\text { Chlorhexidine Improve } \\
\text { Desin- } \\
\text { Dentin Bond Durability: Quan- } \\
\text { titative Analysis Using } \\
\text { Spaman } \\
\text { Spectroscopy }\end{array}$ & $\begin{array}{l}\text { Talungchit, } \\
\text { Supitcha } \\
\text { et al. }\end{array}$ & 2014 & $\begin{array}{l}\text { Analítico } \\
\text { Experimental } \\
\text { (in vitro) }\end{array}$ & $\begin{array}{l}\text { Ethanol-wet bonding (EW) aumenta a infiltração de monómeros } \\
\text { hidrofóbicos na dentina desmineralizada. Os resultados sugerem que } \\
\text { uma ligação de resina-dentina mais durável pode ser conseguida com } \\
\text { o uso combinado de EW e clorexidina. }\end{array}$ \\
\hline $\begin{array}{l}\text { Matrix metalloproteinase inhibi- } \\
\text { tory properties of benzalkonium } \\
\text { chloride stabilizes adhesive in- } \\
\text { terfaces }\end{array}$ & $\begin{array}{l}\text { Sabati } \\
\text { Patel S }\end{array}$ & 2013 & Longitudinal & $\begin{array}{l}\text { O cloreto de benzalcónio (BAC) ou clorexiina reduz a microinfiltração } \\
\text { marginal. }\end{array}$ \\
\hline $\begin{array}{l}\text { Effect of a Chlorhexidine- } \\
\text { containing Adhesive on Dentin } \\
\text { Bond Strength Stability }\end{array}$ & Sabatini C & 2013 & $\begin{array}{l}\text { Analítico } \\
\text { Experimental } \\
\text { (in vitro) }\end{array}$ & $\begin{array}{l}\text { A clorexidina demonstrou inibição da atividade proteolítica da dentina. } \\
\text { No entanto, quando a clorexidina foi incorporada a um adesivo } \\
\text { comercial disponível ou utilizada como um primer terapêutico, não foi } \\
\text { observada diferença na força de ligação na linha de base ou após seis } \\
\text { meses de armazenamento em relação ao grupo controle (sem CHX). }\end{array}$ \\
\hline $\begin{array}{l}\text { Chlorhexidine Application in } \\
\text { Adhesive Procedures: A Meta- } \\
\text { Regression Analysis }\end{array}$ & \begin{tabular}{l|} 
Collares, \\
Fabrício et al.
\end{tabular} & 2013 & $\begin{array}{l}+0 \\
\text { ática }\end{array}$ & $\begin{array}{l}\text { Os resultados mostraram que a associação entre a concentração de } \\
\text { clorexidina e a resistência de ligação é, aparentemente, não linear. } \\
\text { Portanto, estudos futuros em larga escala devem ser desenvolvidos } \\
\text { para investigar a associação entre a concentração de clorexidina e a } \\
\text { preservação da camada híbrida. }\end{array}$ \\
\hline $\begin{array}{l}\text { Does inhibition of proteolytic } \\
\text { activity improve adhesive luting? }\end{array}$ & $\begin{array}{l}\text { Lührs AK } \\
\text { et al. }\end{array}$ & 2013 & $\begin{array}{l}\text { Analítico } \\
\text { Experimental } \\
\text { (in vitro) }\end{array}$ & $\begin{array}{l}\text { Inibidores de atividade enzimática como a clorexidina e o galardin } \\
\text { não foram eficazes em prevenir a redução da resistência adesiva entre } \\
\text { cimentos resinosos e dentina. }\end{array}$ \\
\hline $\begin{array}{l}\text { Evaluating EDTA as a substitute } \\
\text { for phosphoric acid-etching of } \\
\text { enamel and dentin. }\end{array}$ & $\begin{array}{l}\text { Imbery TA } \\
\text { et al. }\end{array}$ & 2012 & $\begin{array}{l}\text { Analítico } \\
\text { Experimental }\end{array}$ & $\begin{array}{l}\text { A clorexidina aplicada inibe a ativação das MMPs liberadas, enquanto } \\
\text { que o ácido tetra-acético etilenodiamina neutro (EDTA) impede a } \\
\text { liberação das MMPs. Assim, no intuito de reduzir os efeitos prejudiciais } \\
\text { das MMPs, o condicionamento do esmalte e da dentina com EDTA é um } \\
\text { alternativa interessante em substituição ao tratamento com clorexidina. }\end{array}$ \\
\hline $\begin{array}{l}\text { MMP-Inhibitory Effect of } \\
\text { Chlorhexidine Applied in a Self- } \\
\text { etching Adhesive }\end{array}$ & \begin{tabular}{l|} 
Zhou, \\
Jianfeng et al.
\end{tabular} & 2011 & $\begin{array}{l}\text { Analítico } \\
\text { Experimental }\end{array}$ & $\begin{array}{l}\text { A clorexidina pode manter, parcialmente, seu efeito inibitório sobre as } \\
\text { MMPs quando incorporada a um primer adesivo auto-condicionante } \\
\text { de dois passos (Clearfil SE Bond iniciador). }\end{array}$ \\
\hline $\begin{array}{l}\text { MMP-2 assay within the hybrid } \\
\text { layer created by a two-step etch- } \\
\text {-and-rinse adhesive: biochemi- } \\
\text { cal and immunohistochemical } \\
\text { analysis }\end{array}$ & $\begin{array}{l}\text { Mazzoni A } \\
\text { et al. }\end{array}$ & 2011 & $\begin{array}{l}\text { Analítico } \\
\text { Experimental }\end{array}$ & $\begin{array}{l}\text { A clorexidina deve ser aplicada como um passo adicional em } \\
\text { procedimentos que envolvam sistemas adesivos a fim de aumentar a } \\
\text { longevidade das restaurações em resinas compostas. }\end{array}$ \\
\hline $\begin{array}{l}\text { Effect of dentin etching and } \\
\text { chlorhexidine application on me- } \\
\text { talloproteinase-mediated colla- } \\
\text { gen degradation }\end{array}$ & $\begin{array}{l}\text { Osorio R } \\
\text { et al. }\end{array}$ & 2011 & $\begin{array}{l}\text { Analítico } \\
\text { Experimental }\end{array}$ & $\begin{array}{l}\text { A ação inibitória parcial da clorexidina na atividade da MMP produzida } \\
\text { por adesivos autocondicionantes foi prolongada em comparação com } \\
\text { o tratamento da dentina com ácido fosfórico de passo único ou EDTA. }\end{array}$ \\
\hline $\begin{array}{l}\text { The inhibitory effects of quaternary } \\
\text { ammonium methacrylates on } \\
\text { soluble and matrix-bound MMPs }\end{array}$ & $\begin{array}{l}\text { Tezvergil- } \\
\text { Mutluay A } \\
\text { et al. }\end{array}$ & 2011 & $\begin{array}{l}\text { Analítico } \\
\text { Experimental }\end{array}$ & $\begin{array}{l}\text { Metacrilatos de amónio quaternário (QAMs) promoveram inibição da } \\
\text { MMP-9, porém, em concentrações mais elevadas que a clorexidina. }\end{array}$ \\
\hline $\begin{array}{l}\text { Evaluation of chlorhexidine on } \\
\text { the quality of the hybrid layer in } \\
\text { noncarious primary teeth: an in } \\
\text { vitro study }\end{array}$ & $\begin{array}{l}\text { Azevedo TD } \\
\text { et al. }\end{array}$ & 2010 & $\begin{array}{l}\text { Analítico } \\
\text { Experimental }\end{array}$ & $\begin{array}{l}\text { Os resultados demonstraram que o protocolo clínico restaurador } \\
\text { com a utilização da aplicação de clorexidina não interfere de forma } \\
\text { significativa nas características morfológicas da camada híbrida. }\end{array}$ \\
\hline $\begin{array}{l}\text { The incorporation of chlorhexidine } \\
\text { in a two-step self-etching adhesive } \\
\text { preserves dentin bond in vitro }\end{array}$ & Zhou J et al & 2009 & $\begin{array}{l}\text { Analítico } \\
\text { Experimental }\end{array}$ & $\begin{array}{l}\text { Quando incorporada no primer do Clearfil SE Bond, a clorexidina } \\
\text { pode preservar a dentina, desde que a sua concentração no primer } \\
\text { seja maior ou igual a } 0,1 \% \text {. }\end{array}$ \\
\hline $\begin{array}{l}\text { Ethanol wet-bonding challenges } \\
\text { current anti-degradation strategy }\end{array}$ & Sadek FT et al & 2010 & Longitudinal & $\begin{array}{l}\text { A eficácia em longo prazo da clorexidina como um inibidor da } \\
\text { metaloproteinase da matriz (MMP) pode ser comprometida, caso } \\
\text { a água não seja completamente removida durante a aplicação do } \\
\text { sistema adesivo. }\end{array}$ \\
\hline $\begin{array}{l}\text { Chlorhexidine stabilizes the } \\
\text { adhesive interface: a 2-year in } \\
\text { vitro study }\end{array}$ & $\begin{array}{l}\text { Breschi L } \\
\text { et al }\end{array}$ & 2010 & Longitudinal & $\begin{array}{l}\text { O pré-tratamento com clorexidina inibiu toda a atividade gelatinolítica } \\
\text { na dentina, independe da concentração testada. A CHX reduziu } \\
\text { significativamente a perda da força de ligação e a nanoinfiltração na } \\
\text { interface dentina-resina envelhecida artificialmente por } 2 \text { anos. }\end{array}$ \\
\hline $\begin{array}{l}\text { Host-derived loss of dentin matrix } \\
\text { stiffness associated with solubiliza- } \\
\text { tion of collagen }\end{array}$ & $\begin{array}{l}\text { Carrilho MR } \\
\text { et al. }\end{array}$ & 2009 & $\begin{array}{l}\text { Analítico } \\
\text { Experimental }\end{array}$ & $\begin{array}{l}\text { A atividade colagenolítica foi significativamente reduzida pelo } \\
\text { pré-tratamento com } \mathrm{CHX} \text { a } 2 \% \text {. }\end{array}$ \\
\hline
\end{tabular}




\section{Discussão}

\section{Mecanismo de ação das MMP sobre a degradação do colágeno}

A dentina contém uma variedade de enzimas que podem interferir na adesão de materiais restauradores, destacando-se as metaloproteinases (MMPs) descritas pela primeira vez em 1962 por Gross \& Lapiere ${ }^{19}$. As MMPs são retidas na matriz extracelular da dentina mineralizada durante o desenvolvimento dos dentes ${ }^{3,4}$ e pertencem ao grupo das endopeptidases ${ }^{20}$. Atualmente, já foram descritas 24 MMPs na espécie humana ${ }^{21}$.

As MMPs participam de importantes mecanismos biológicos, como o processamento de fatores de crescimento, e em diversos processos patológicos ${ }^{22}$. Além disso, as MMPs têm papel fundamental no desenvolvimento e remodelação dos tecidos orais. Há um consenso de que as MMPs da matriz da dentina são fundamentais para a dentinogênese $e^{5,6,23}$. Por outro viés, essas enzimas também são responsáveis pela degradação dos componentes extracelulares da dentina após uma variação de $\mathrm{pH}$ tecidual. Depois da mineralização da matriz de colágeno, as formas inativas de MMPs permanecem presas dentro da matriz calcificada ${ }^{22}$, porém podem ser re-expostas e, potencialmente, ativadas durante o processo carioso. $\mathrm{O}$ ambiente ácido criado pelas bactérias pode facilitar a ativação das MMPs endógenas. Logo, indivíduos que mostram maior suscetibilidade à cárie e à erosões dentinárias apresentam grandes concentrações de MMPs na saliva ${ }^{21}$. A ativação das metaloproteinases MMP-2, MMP-8 e MMP-9 desempenham um importante papel na degradação do colágeno em lesões cariosas, incluindo colágeno fibrilar e não-fibrilar, fibronectina, laminina e glicoproteínas da membrana basal.

Mesmo após o uso de sistemas adesivos, as MMPs ativadas são capazes de degradar a matriz de colágeno da dentina desmineralizada. Ácidos fracos são conhecidos por ativar MMPs na dentina ${ }^{24}$. Esse fato ocorre comumente porque todos os sistemas adesivos, seja, autocondicionante ou convencional $^{24,25}$, têm a capacidade de reativar gelatinases (MMP-2 e MMP-9) e colagenases na dentina desmineralizada ${ }^{26}$.

Durante o estabelecimento da camada híbrida, a remoção do conteúdo mineral da superfície da dentina, além de expor fibrilas de colágeno, também libera proteases aprisionadas no processo de mineralização do tecido dentinário, como as MMPs ${ }^{18}$. Essas enzimas hidrolisam o colágeno não protegido pelo sistema adesivo no interior da camada híbrida ${ }^{27}$, levando à redução da resistência de adesão entre a restauração adesiva e a dentina ${ }^{28}$. Essa degradação é um fator de risco à integridade da interface dente-restauração $0^{2,12,24,25}$.
Não obstante, as MMPs podem contribuir para o desenvolvimento de algumas doenças e má formação dos tecidos bucais. A MMP-8 é conhecida por estar envolvida em doenças periodontais e a MMP20 participa do desenvolvimento da fluorose e amelogênese imperfeita ${ }^{4,29}$.

\section{Uso da clorexidina na inativação das MMPs e seu impacto na adesividade de restaurações em resina composta}

A degradação de matrizes de colágeno pode ocorrer após os procedimentos restauradores, mas pode ser impedida pela aplicação de uma protease sintética inibidora, como a clorexidina $(\mathrm{CHX})^{12}$. A CHX atua como inibidor não específico das MMPs, ao alterar a estrutura tridimensional dessas enzimas e quelar os íons metálicos (Ca2+, Zn2+) que são necessários para a ativação de sua função enzimática $^{9}$. A CHX é capaz de inativar todas as MMPs existentes na dentina mesmo em baixa concentração $(0,02 \%)$. Além disso, esta substância tem a vantagem de possuir elevada substantividade ${ }^{12}$, propriedade que permite que tal substância permaneça na cavidade bucal por um tempo adequado.

Estudos experimentais in vitro ${ }^{30}$ e in vivo ${ }^{31} \mathrm{com}-$ provaram que a aplicação da clorexidina após o condicionamento ácido, reduz a velocidade de degradação da ligação entre o dente e o sistema adesivo, proporcionando, dessa forma, a manutenção do selamento dentinário e uma adequada resistência da adesão por um período de tempo mais prolongado.

A concentração mínima de CHX que promove inibição completa da atividade da MMP-9 é de $0,002 \%$, no entanto, a atividade da MMP-2 é muito mais sensível, sendo inibida por uma concentração de $0,0001 \%$, contudo, a MMP-8 pode ser inibida por uma concentração maior $(0,02 \%)$. Entretanto, a atividade colagenolítica da dentina pode ser inibida com a aplicação de clorexidina a $0,2 \%$ durante 60 segundos ${ }^{30}$.

A clorexidina deve ser aplicada por meio de solução aquosa pura, ao invés da sua solução convencional, que, geralmente, contêm conservantes, podendo, assim, afetar, negativamente, a ligação adesiva. Essa solução deve ser aplicada com o auxílio de uma pelota de algodão, após a remoção completa do ácido fosfórico a $37 \%$, permanecendo no local por 60 segundos. Após esse passo, o excesso de umidade da cavidade, provocado pelo uso da clorexidina, é removido com suaves jatos de ar e o adesivo inserido ${ }^{12,32}$.

$\mathrm{O}$ álcool contido no adesivo não dissolve a $\mathrm{CHX}$, que, por sua vez, não prejudicar as propriedades de ligação da interface dente-restauração e permitir a formação de uma camada híbrida regular ${ }^{12}$. A força de união adesiva imediata não é alterada pela aplicação da CHX, porém essa ligação adesiva se perpetua por um período de tempo maior, pois há uma redução no processo de nanoinfiltração ${ }^{28,31}$. Vale res- 
saltar, que o tempo máximo de avaliação da maioria dos estudos é curto, logo, pouco se sabe sobre o período de tempo limite que a CHX pode manter o seu efeito inibidor sobre as MMPs, sendo necessário mais estudos sobre o assunto para elucidar esse aspecto.

Atualmente, há tentativas de integrar a CHX ao ácido fosfórico ou ao agente de ligação $0^{3,16}$, pois esses agentes teriam a grande vantagem de, durante o processo de restauração, não necessitar de alguma substância adicional excluindo um passo do trabalho necessário para a criação de uma ligação adesiva. Por exemplo, um estudo experimental in vitro ${ }^{33}$ mostrou que a incorporação de $2 \%$ de CHX a $37 \%$ do ácido fosfórico tem resultados semelhantes aos obtidos com a utilização de CHX como primer terapêutico. Em ambas as formas de aplicação da CHX, a ligação adesiva à dentina manteve-se estável durante os primeiros seis meses, enquanto que no grupo-controle (sem a utilização de CHX) os sinais de desintegração da camada híbrida já eram reconhecíveis ${ }^{28}$.

\section{Considerações finais}

O uso da clorexidina, após o condicionamento ácido, previne a ativação da enzima metaloproteinase que degrada a rede de colágeno, causando falhas em restaurações adesivas. Porém, ensaios clínicos randomizados devem ser realizados de modo que se obtenha melhores evidencias científicas quanto à dose, tempo de exposição e efetividade na redução da microinfiltração marginal.

\section{Abstract}

Objective: to analyze the mechanism of action of chlorhexidine on the matrix metalloproteinases (MMPs) enzymes and their clinical impact. Materials and method: the search strategy included Medline, Lilacs, and Pubmed databases. The articles were selected based on the following criteria: be written in English, Spanish, or Portuguese, be formatted as an original article, have abstracts available, address issues that relate MMPs to adhesive systems and/or the influence of chlorhexidine on these enzymes, and be published between 2005 and 2015. Results: 34 articles were found, but only 18 studies were included after the critical analysis of abstracts. Final considerations: the use of chlorhexidine as a therapeutic primer after acid etching prevents activating the metalloproteinase enzyme that degrades the collagen network, causing failure in adhesive restorations. Therefore, the use of this substance must be encouraged to avoid adhesive failure in restorations, increasing their lifetime.

Keywords: Chlorhexidine. Collagen. Dentin. Restoration.

\section{Referências}

1. Talungchit S, Jessop JL, Cobb DS, Qian F, Geraldeli S, Pashley DHet al. Ethanol-wet bonding and chlorhexidine improve resin-dentin bond durability: quantitative analysis using raman spectroscopy. J Adhes Dent 2014;16(5):441-50.

2. Breschi L, Mazzoni A, Nato F, Carrilho M, Visintini E, Tjäderhane $\mathrm{L}$ et al. Chlorhexidine stabilizes the adhesive interface: a 2-year in vitro study. Dent Mater 2010; 26(4):320-5.

3. Zhou J, Tan J, Yang X, Xu X, Li D, Chen L. MMP-inhibitory effect of chlorhexidine applied in a self-etching adhesive. J Adhes Dent 2011;13(2):111-5.

4. Zhang SC, Kern M. The role of host-derived dentinal matrix metalloproteinases in reducing dentin bonding of resin adhesives. Int J Oral Sci 2009;1(4):163-76.

5. Strobel S, Hellwig E. The effects of matrix-metallo- proteinases and chlorhexidine on the adhesive bond. Swiss Dent J 2015;125(2):134-45

6. Sabatini C. Effect of a chlorhexidine-containing adhesive on dentin bond strength stability. Oper Dent 2013;38(6):609-17.

7. Imbery TA, Kennedy M, Janus C, Moon PC. Evaluating EDTA as a substitute for phosphoric acid-etching of enamel and dentin. Gen Dent 2012;60(2):e55-61.

8. Mazzoni A, Carrilho M, Papa V, Tjäderhane L, Gobbi P, Nucci $\mathrm{C}$ et al. MMP-2 assay within the hybrid layer created by a two-step etch-and-rinse adhesive: biochemical and immunohistochemical analysis. J Dent 2011;39(7):470-7.

9. Osorio R, Yamauti M, Osorio E, Ruiz-Requena ME, Pashley $\mathrm{D}$, Tay $\mathrm{F}$ et al. Effect of dentin etching and chlorhexidine application on metalloproteinase-mediated collagen degradation. Eur J Oral Sci 2011;119(1):79-85.

10. Tezvergil-Mutluay A, Agee KA, Uchiyama T, Imazato S, Mutluay MM, Cadenaro $\mathrm{M}$ et al. The inhibitory effects of quaternary ammonium methacrylates on soluble and matrix-bound MMPs. J Dent Res 2011;90(4):535-40.

11. Lührs AK, De Munck J, Geurtsen W, Van Meerbeek B. Does inhibition of proteolytic activity improve adhesive luting? Eur J Oral Sci 2013;121(2):121-31.

12. Carrilho MR, Tay FR, Donnelly AM, Agee KA, Tjäderhane L, Mazzoni A et al. Host-derived loss of dentin matrix stiffness associated with solubilization of collagen. J Biomed Mater Res B Appl Biomater 2009;90(1):373-80.

13. Mazzoni A, Tjäderhane L, Checchi V, Di Lenarda R, Salo T, Tay FR et al. Role of dentin MMPs in caries progression and bond stability. J Dent Res 2015;94(2):241-51.

14. Sabatini C, Patel SK. Matrix metalloproteinase inhibitory properties of benzalkonium chloride stabilizes adhesive interfaces. Eur J Oral Sci 2013;121(6):610-6.

15. Sadek FT, Braga RR, Muench A, Liu Y, Pashley DH, Tay FR. Ethanol wet-bonding challenges current anti-degradation strategy. J Dent Res 2010;89(12):1499-504.

16. Zhou J, Tan J, Yang X, Cheng C, Wang X, Chen L. Effect of chlorhexidine application in a self-etching adhesive on the immediate resin-dentin bond strength. J Adhes Dent 2010;12(1):27-31

17. Collares FM, Rodrigues SB, Leitune VC, Celeste RK, Borba de Araújo F, Samuel SM. Chlorhexidine application in adhesive procedures: a meta-regression analysis. J Adhes Dent 2013;15(1):11-8.

18. Azevedo TD, Bezerra AC, Faber J, de Toledo OA. Evaluation of chlorhexidine on the quality of the hybrid layer in noncarious primary teeth: an in vitro study. J Dent Child (Chic) 2010;77(1):25-31. 
19. Gross J, Lapiere CM. Collagenolytic activity in amphibian tissues: a tissue culture assay. Proc Natl Acad Sci U S A 1962;15(48):1014-22.

20. Mazzoni A, Nascimento FD, Carrilho M, Tersariol I, Papa V, Tjäderhane L et al. MMP activity in the hybrid layer detected with in situ zymography. J Dent Res 2012;91(5):467-72.

21. Chaussain C, Boukpessi T, Khaddam M, Tjaderhane L, George A, Menashi S. Dentin matrix degradation by host matrix metalloproteinases: inhibition and clinical perspectives toward regeneration. Front Physiol 2013;1(4):308.

22. Fonceca AS. Odontologia Estética: Respostas às Dúvidas mais Frequentes. Artes Medicas; 2014.

23. Martin-De Las Heras S, Valenzuela A, Overall CM. The matrix metalloproteinase gelatinase A in human dentine. Arch Oral Biol 2000;45(9):757-65.

24. Nishitani Y, Yoshiyama M, Wadgaonkar B, Breschi L, Mannello F, Mazzoni A et al. Activation of gelatinolytic/collagenolytic activity in dentin by self-etching adhesives. Eur J Oral Sci 2006;114(2):160-6.

25. Mazzoni A, Pashley DH, Nishitani Y, Breschi L, Mannello F, Tjäderhane $\mathrm{L}$ et al. Reactivation of inactivated endogenous proteolytic activities in phosphoric acid-etched dentine by etch-and-rinse adhesives. Biomaterials 2006;27(25):4470-6.

26. Mazzoni A, Mannello F, Tay FR, Tonti GA, Papa S, Mazzotti G et al. Zymographic analysis and characterization of MMP-2 and -9 forms in human sound dentin. J Dent Res 2007;86(5):436-40.

27. Hebling J, Pashley DH, Tjäderhane L, Tay FR. Chlorhexidine arrests subclinical degradation of dentin hybrid layers in vivo. J Dent Res 2005;84(8):741-6.

28. De Munck J, Van Meerbeek B, Yoshida Y, Inoue S, Vargas M, Suzuki K et al. Four-year water degradation of total-etch adhesives bonded to dentin. J Dent Res 2003;82(2):136-40.

29. Hannas AR, Pereira JC, Granjeiro JM, Tjäderhane L. The role of matrix metalloproteinases in the oral environment. Acta Odontol Scand 2007;65(1):1-13.

30. Pashley DH, Tay FR, Yiu C, Hashimoto M, Breschi L, Carvalho RM et al. Collagen degradation by host-derived enzymes during aging. J Dent Res 2004;83(3):216-21.

31. Carrilho MR. Can exogenous protease inhibitors control dentin matrix degradation? J Dent Res 2012;91(12):1099-102.

32. Tay FR, Pashley DH, Loushine RJ, Weller RN, Monticelli F, Osorio R. Self-etching adhesives increase collagenolytic activity in radicular dentin. J Endod 2006;32(9):862-8.

33. Stanislawczuk R, Amaral RC, Zander-Grande C, Gagler D, Reis A, Loguercio AD. Chlorhexidine-containing acid conditioner preserves the longevity of resin-dentin bonds. Oper Dent 2009;34(4):481-90.

\section{Endereço para correspondência:}

Valdeci Elias dos Santos Junior Rua São Sebastião 417 apto 101 Piedade Jaboatão dos Guararapes-PE Brasil. Fone: (81) 97446105

E-mail: valdeciodonto@gmail.com

Recebido: 21/01/2016. Aceito: 19/01/2017. 